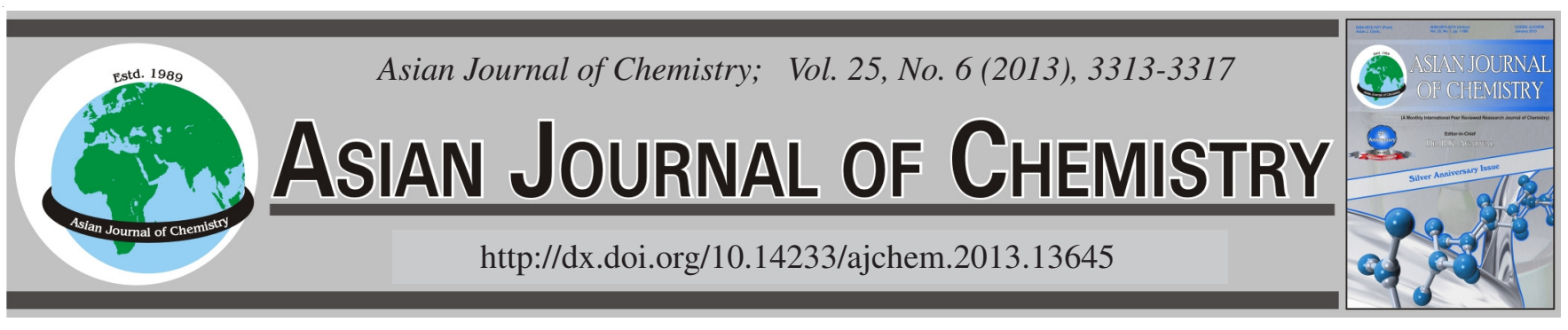

\title{
Advanced Treatment of Industrial Wastewater by Heterogeneous Fenton Reaction Using a Novel Composite Catalyst
}

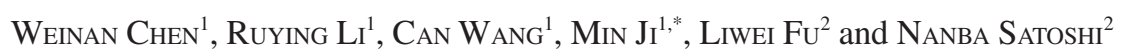

${ }^{1}$ School of Environmental Science and Engineering, Tianjin University, Tianjin, P.R. China

${ }^{2}$ Mitsubishi Gas Chemical Co., Ltd. Tokyo, Japan

*Corresponding author: Fax: +86 22 27406057; Tel: +86 22 27406057; E-mail: jimin@tju.edu.cn; cwn_cwn@126.com

(Received: 22 February 2012;

Accepted: 17 December 2012)

AJC-12574

\begin{abstract}
Using a novel composite catalyst OR-SON, advanced treatment of mixed industrial wastewater was investigated by $\mathrm{OR}-\mathrm{SON} / \mathrm{H}_{2} \mathrm{O}_{2}$ as the heterogeneous Fenton reagent. The impact factors on COD degradation under traditional Fenton conditions, such as HRT and the dosage of $\mathrm{FeSO}_{4} \cdot 7 \mathrm{H}_{2} \mathrm{O}$ were investigated. Effects of $\mathrm{pH}, \mathrm{HRT}$, catalyst consumption on the catalytic oxidation capacity of OR-SON were evaluated. Comparison between heterogeneous Fenton oxidation (catalyzed by OR-SON) and traditional Fenton oxidation was also investigated. Results showed that addition of OR-SON could enhance the oxidation ability of $\mathrm{H}_{2} \mathrm{O}_{2}$, significantly improved the reaction rate of the reaction system and dramatically increased the removal rate of COD. Meanwhile, the dosage of $\mathrm{FeSO}_{4} \cdot 7 \mathrm{H}_{2} \mathrm{O}$ of the $\mathrm{OR}-\mathrm{SON} / \mathrm{H}_{2} \mathrm{O}_{2}$ system was only one tenth of the homogeneous Fenton system, which reduced the production of iron containing sludge greatly. Besides, experiments also showed that OR-SON could be recycled under certain conditions.
\end{abstract}

Key Words: Industrial wastewater, Catalytic oxidation, OR-SON, Heterogeneous Fenton.

\section{INTRODUCTION}

Fenton technology is a well-known process and has been reported as an effective alternative for the treatment of the industrial wastewater containing non-biodegradable organic pollutants ${ }^{1}$. Fenton reagents involve the generation of hydroxyl radicals via homogeneous reaction between hydrogen peroxide and ferrous ion and they are easy to operate and maintain ${ }^{2}$. Hydroxyl radical, a very strong and non-specific oxidant, is generated by the $\mathrm{Fe}$ (II)-catalyzed decomposition of hydrogen peroxide. However, their overall efficiency is limited with significant disadvantages $^{3}$ : (1) generates iron hydroxide sludge which may demand further steps to comply with environmental regulations; (2) the tight range of $\mathrm{pH} 2-3$ which requires strong conditioning before and after treatment; (3) iron ions may be deactivated due to the complex agents like phosphate anions and some intermediate oxidation products.

One of the most practical and interesting ways proposed to overcome these limitations is to use Fenton-like heterogeneous catalysts. In heterogeneous solid catalysts, the iron ions are "immobilized" on the solid supports or within the structure and in the pore/interlayer of the catalysts ${ }^{4}$. As a result, the catalysts can maintain its ability to generate hydroxyl radicals from hydrogen peroxide. Besides showing limited leaching of iron ions, the catalysts can be easily recovered after the reaction and remain active during successive operations ${ }^{5}$. In Fenton-like system, the formation of hydroxyl radical is due to the $\mathrm{Fe}^{2+}$ catalyzed decomposition of $\mathrm{H}_{2} \mathrm{O}_{2}$ on the surface of the support where the iron species bound to the surface of the catalyst ${ }^{6,7}$ :

$$
\begin{aligned}
& \mathrm{Fe}^{3+}+\mathrm{H}_{2} \mathrm{O}_{2} \rightarrow \mathrm{Fe}^{2+}+\mathrm{HOO}^{\circ}+\mathrm{H}^{+} \\
& \mathrm{Fe}^{2+}+\mathrm{H}_{2} \mathrm{O}_{2} \rightarrow \mathrm{Fe}^{3+}+{ }^{\circ} \mathrm{OH}+\mathrm{OH}^{-}
\end{aligned}
$$

A number of heterogeneous solid catalysts, including iron minerals ${ }^{8}$, crystalline $\mathrm{Fe}_{2} \mathrm{O}_{3} / \mathrm{SBA}-15$ nano-composite ${ }^{9}$ or transition metals ions immobilized on solid supports such as alumina $^{10}$, zeolites ${ }^{5}$, pillared clays ${ }^{11}$, ion exchange resin ${ }^{12}$ and activated carbon ${ }^{13}$ have been investigated. To some extent, these heterogeneous solid catalysts can solve the problem of the homogeneous catalysts. However, they also have obvious disadvantages as follows ${ }^{14}$ : (1) relative low catalytic efficiency; (2) low strength and quite fragile; (3) due to the leaching of iron ions, iron hydroxide precipitation would be generated. Therefore, the application of heterogeneous catalysts has also been limited.

In this study, a novel heterogeneous catalysts named as OR-SON, which was produced by Mitsubishi Gas Chemical Co., Ltd. was investigated in advanced treatment of mixed industrial wastewater of a chemical industrial park in Tianjin. The catalytic mechanism and the adsorption capacity of ORSON were studied and the proper reaction conditions of the 
OR-SON Fenton system were investigated. Besides, comparison between heterogeneous Fenton oxidation (catalyzed by OR-SON) and traditional Fenton oxidation was also investigated and the service life of OR-SON was evaluated.

\section{EXPERIMENTAL}

Raw wastewater quality: The raw wastewater was the effluent of the sedimentation tank of an industrial wastewater treatment plant which was mainly used for degrading the industrial wastewater of a chemical industrial park in Tianjin. The effluent used in this study was treated by a biochemical process, but after this treatment process, the effluent could not meet the discharge standard of pollutants for municipal wastewater treatment plant (GB18918-2002). The characteristics of the raw wastewater were shown in Table-1.

\begin{tabular}{cccccc}
\multicolumn{7}{c}{ TABLE-1 } \\
\hline $\begin{array}{c}\mathrm{COD} \\
(\mathrm{mg} / \mathrm{L})\end{array}$ & $\begin{array}{c}\mathrm{BOD}_{5} \\
(\mathrm{mg} / \mathrm{L})\end{array}$ & $\mathrm{pH}$ & $\begin{array}{c}\mathrm{NH}_{3}-\mathrm{N} \\
(\mathrm{m} / \mathrm{L})\end{array}$ & $\begin{array}{c}\mathrm{NO}_{3}^{-}-\mathrm{N} \\
(\mathrm{mg} / \mathrm{L})\end{array}$ & $\begin{array}{c}\text { Total nitrogen } \\
(\mathrm{mg} / \mathrm{L})\end{array}$ \\
\hline $100-120$ & $15-20$ & $7.5-8$ & $15-20$ & $5-6$ & $22-30$ \\
\hline
\end{tabular}

FeSO ${ }_{4} \cdot 7 \mathrm{H}_{2} \mathrm{O}$ and $\mathrm{H}_{2} \mathrm{O}_{2}(30$ wt $\%)$ were used in this study. All the chemical reagents were analytically pure reagent. Besides, the OR-SON was provided by Mitsubishi Gas Chemical Co. Ltd. and its concentration was controlled by the manufactory. pH was detected by an Sartorius PT-10 pH meter. And a six joint mixer (Phipps \& Bird, PB-700, USA) was used in this study for stirring the wastewater, so that the Fenton reagent could contact with the pollutant efficiently.

Methods: (1) Take $1000 \mathrm{~mL}$ raw wastewater into a $1 \mathrm{~L}$ beaker and adjust $\mathrm{pH}$ to the certain value using sulphuric acid (20 vol \%); (2) Add a certain amount of $\mathrm{FeSO}_{4} \cdot 7 \mathrm{H}_{2} \mathrm{O}$ and OR-SON into the raw wastewater and place the beaker on the six joint mixer; (3) Add a certain amount of $\mathrm{H}_{2} \mathrm{O}_{2}$ solution and then turn on the six joint mixer to start the reaction; (4) After the reaction complete, take $500 \mathrm{~mL}$ supernatant out of the beaker after $0.5 \mathrm{~h}$ static settlement and adjust the $\mathrm{pH}$ to 10 using $\mathrm{NaOH}$ (10\% wt); (5) After static settlement, the supernatant is filtered by a vacuum filter $(0.45 \mu \mathrm{m}$ membrane filter $)$ and then the filtered water is collected to be analyzed.

\section{RESULTS AND DISCUSSION}

\section{Performance of traditional Fenton reagent}

Effect of the dosage of $\mathrm{FeSO}_{4} \cdot \mathbf{7 H}_{2} \mathrm{O}$ : Effect of the dosage of $\mathrm{FeSO}_{4} \cdot 7 \mathrm{H}_{2} \mathrm{O}$ on the performance of traditional Fenton oxidation was investigated and the result was shown in Fig. 1. The initial $\mathrm{pH}$ of the raw wastewater was $\mathrm{pH} 3$, the dosage of $\mathrm{H}_{2} \mathrm{O}_{2}$ was $50 \mathrm{mg} / \mathrm{L}$ and reaction time was $2 \mathrm{~h}$.

In this study, the dosage of $\mathrm{FeSO}_{4} \cdot 7 \mathrm{H}_{2} \mathrm{O}$ increased gradually with the molar ratio of $\mathrm{Fe}^{2+}$ and $\mathrm{H}_{2} \mathrm{O}_{2}$ from 1:1-6:1. The initial COD of the raw wastewater was $110 \mathrm{mg} / \mathrm{L}$ and the effluent COD decreased firstly and then increased. When the $\mathrm{Fe}^{2+} / \mathrm{H}_{2} \mathrm{O}_{2}$ ratio was $2: 1$, the highest COD removal efficiency of $35.5 \%$ was obtained, with the effluent COD of $71 \mathrm{mg} / \mathrm{L}$. Results show that the proper molar ratio of $\mathrm{Fe}^{2+}$ and $\mathrm{H}_{2} \mathrm{O}_{2}$ was $2: 1$. When the $\mathrm{Fe}^{2+}$ concentration was too high, $\mathrm{Fe}^{2+}$ would

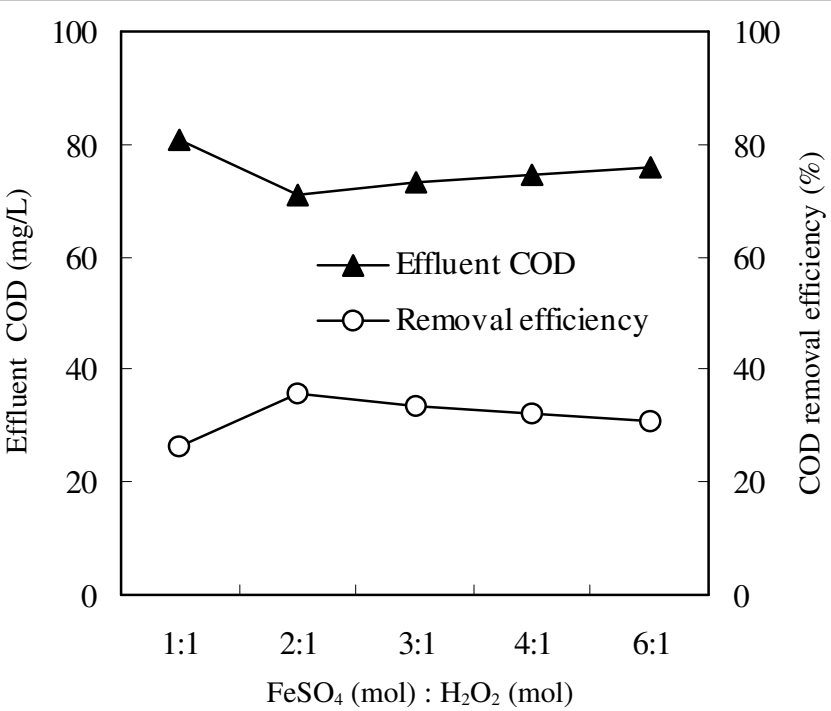

Fig. 1. Effect of different dosage of $\mathrm{FeSO}_{4} \cdot 7 \mathrm{H}_{2} \mathrm{O}$ on the performance of traditional Fenton oxidation

consume the ${ }^{\bullet} \mathrm{OH}$ which was produced by the Fenton reagent, resulting in less ${ }^{\circ} \mathrm{OH}$ to degrade organic compounds. On the other hand, when the concentration of $\mathrm{Fe}^{2+}$ was too low, the production rate of the ${ }^{\circ} \mathrm{OH}$ was lower and the chain reaction of the Fenton system would be limited and thereby oxidation capacity of Fenton system would be attenuated.

Effect of reaction time: Effect of reaction time on the performance of traditional Fenton system was investigated and the result was shown in Fig. 2. The initial $\mathrm{pH}$ of the raw wastewater was $\mathrm{pH} 3$, the dosage of $\mathrm{H}_{2} \mathrm{O}_{2}$ was $100 \mathrm{mg} / \mathrm{L}$ and the molar ratio of $\mathrm{Fe}^{2+}$ and $\mathrm{H}_{2} \mathrm{O}_{2}$ was 2:1.

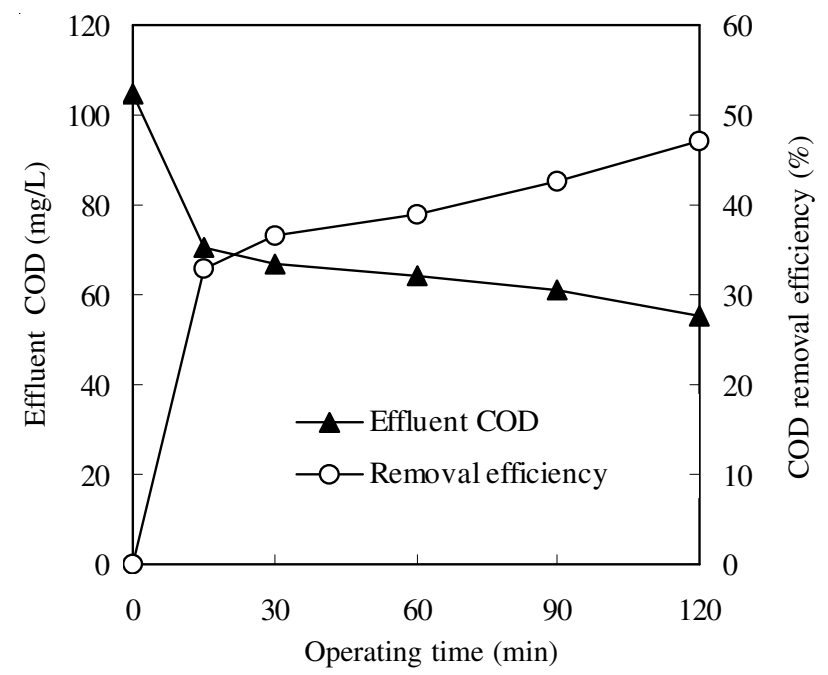

Fig. 2. Effect of reaction time on the performance of traditional Fenton oxidation

In this study, the initial COD of the raw wastewater was $105 \mathrm{mg} / \mathrm{L}$. At the initial stage of the Fenton reaction, the degradation rate of the organic compounds was high and $33 \%$ of COD was removed after 15 min. As shown in Fig. 2, the COD removal efficiency increased with reaction time. After $2 \mathrm{~h}$, the highest COD removal efficiency of $47.2 \%$ was obtained with the effluent COD of $55.4 \mathrm{mg} / \mathrm{L}$. Thus, for traditional Fenton oxidation, the proper reaction time was $2 \mathrm{~h}$. 


\section{Effect of the adsorption capacity of OR-SON}

Effect of the dosage of OR-SON: Effect of different dosage of OR-SON on the adsorption capacity of OR-SON was investigated and the result was shown in Fig. 3. The initial $\mathrm{pH}$ of the raw wastewater was $\mathrm{pH} 3$ and the reaction time was $1 \mathrm{~h}$. Besides, $\mathrm{H}_{2} \mathrm{O}_{2}$ and $\mathrm{FeSO}_{4} \cdot 7 \mathrm{H}_{2} \mathrm{O}$ were not added in to the reaction system.

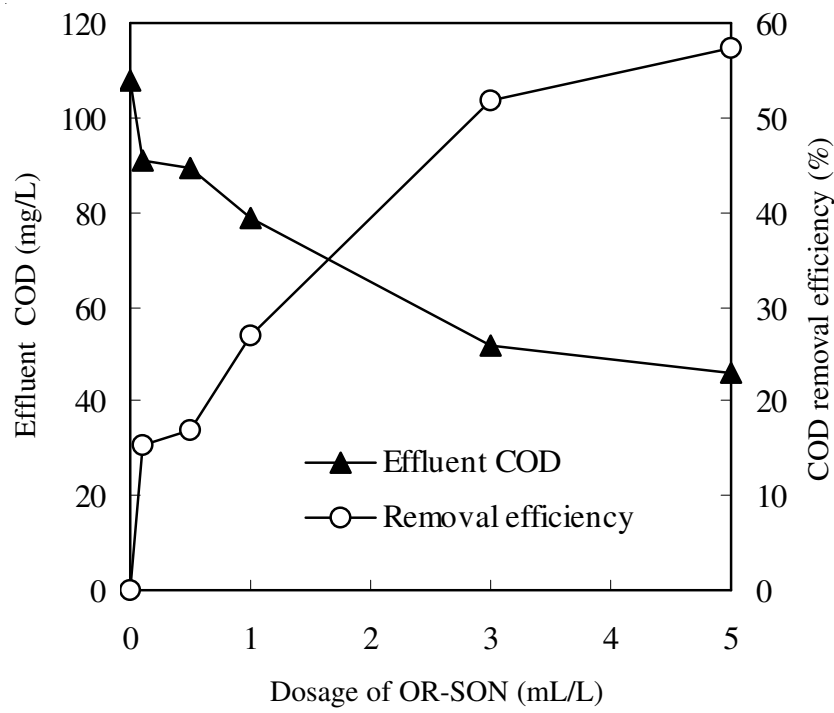

Fig. 3. Effect of different dosage of OR-SON on the adsorption capacity of OR-SON

As for heterogeneous Fenton reaction mechanism, $\mathrm{He}$ et al. ${ }^{15}$ assumed that organic compounds and $\mathrm{H}_{2} \mathrm{O}_{2}$ firstly spread to the surface of the catalyst and then be adsorbed by the activity center of the catalyst. Then ${ }^{\circ} \mathrm{OH}$, which could oxidize the organic compounds into carbon dioxide and water or other biodegradable organic, was produced by heterogeneous Fenton system. At last, the products of heterogeneous Fenton oxidation were spread from the surface of the catalyst into the solution.

In this study, OR-SON had a strong absorption capacity to the organic pollutants. The initial COD of the raw wastewater was $107 \mathrm{mg} / \mathrm{L}$ and the COD removal efficiency continuously increased with increasing OR-SON dosage. However, beyond a certain dosage of the OR-SON, the COD removal efficiency would be stabilized. When the dosage of OR-SON was increased from 3-5 mL/L, the effluent COD decreased from $51.8-45.8 \mathrm{mg} / \mathrm{L}$ and the COD removal efficiency was 51.6 and $57.2 \%$, respectively, with only $5.6 \%$ increase. Thus, as for adsorption reaction, the proper dosage of OR-SON could be $3 \mathrm{~mL} / \mathrm{L}$.

Effect of $\mathrm{pH}$ on the adsorption capacity of OR-SON: Effect of $\mathrm{pH}$ on the adsorption capacity of OR-SON was investigated and the result was shown in Fig. 4. The dosage of OR-SON was $3 \mathrm{~mL} / \mathrm{L}$ and the reaction time was 1 h. $\mathrm{H}_{2} \mathrm{O}_{2}$ and $\mathrm{FeSO}_{4} \cdot 7 \mathrm{H}_{2} \mathrm{O}$ were not added in to the reaction system.

In this study, the initial COD of the raw wastewater was $110 \mathrm{mg} / \mathrm{L}$. When the initial $\mathrm{pH}$ was adjusted to $\mathrm{pH} 3$, organic compounds were adsorbed by OR-SON obviously and the effluent COD was $56.3 \mathrm{mg} / \mathrm{L}$, with removal efficiency of 48.8 $\%$. However, when $\mathrm{pH}$ was adjusted to neutral, the effluent

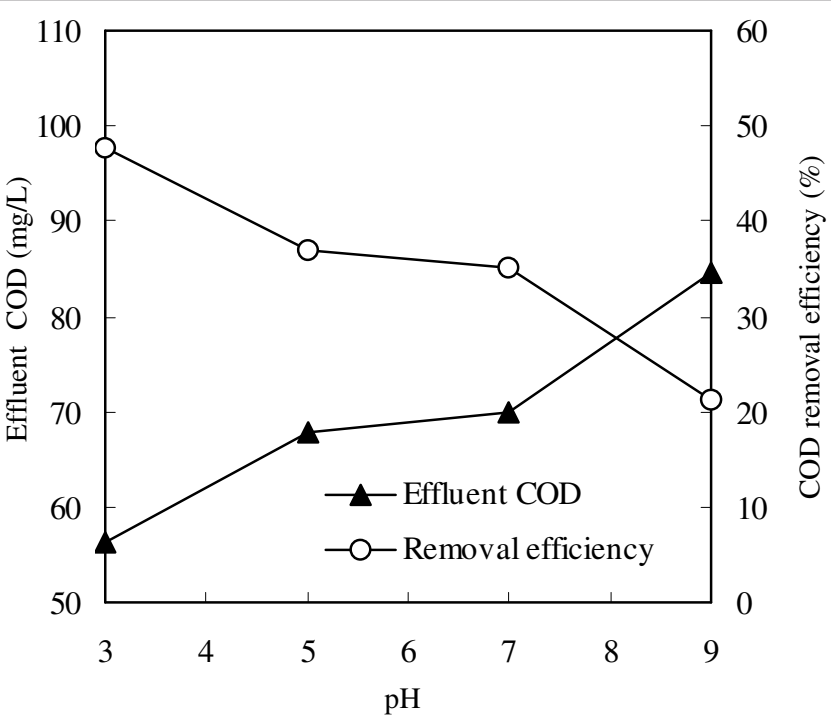

Fig. 4. Effect of $\mathrm{pH}$ on the adsorption capacity of OR-SON

COD increased sharply. When $\mathrm{pH}$ was adjusted to $\mathrm{pH}$ 9, the adsorption capacity of OR-SON was inhibited dramatically, with dramatic increase of effluent COD to $84.6 \mathrm{mg} / \mathrm{L}$. Therefore, it could be assumed that $\mathrm{pH}$ had an obvious effect on the adsorption capacity of OR-SON. At acidic condition, the organic pollutants could be adsorbed effectively. So the proper pH was $\mathrm{pH} 3$.

Effect of reaction time: Effect of reaction time on the adsorption capacity of OR-SON was investigated and the result was shown in Fig. 5. The dosage of OR-SON was $3 \mathrm{~mL} / \mathrm{L}$ and $\mathrm{pH}$ was adjusted to $\mathrm{pH} 3 . \mathrm{H}_{2} \mathrm{O}_{2}$ and $\mathrm{FeSO}_{4} \cdot 7 \mathrm{H}_{2} \mathrm{O}$ were not added in to the reaction system.

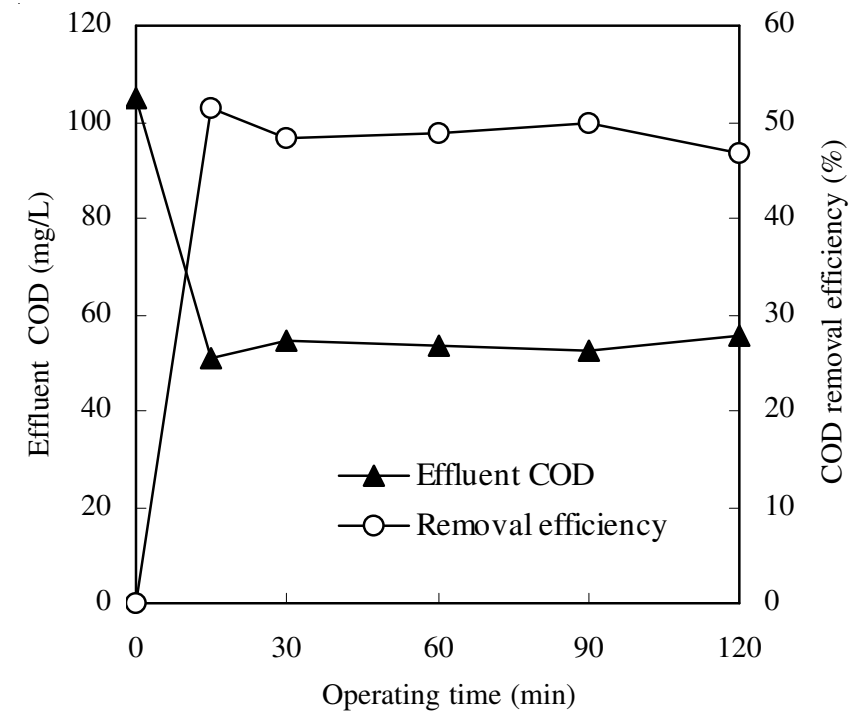

Fig. 5. Effect of reaction time on the adsorption capacity of OR-SON

As shown in Fig. 5, the initial COD of the raw wastewater was $108 \mathrm{mg} / \mathrm{L}$, under certain dosage of OR-SON, the organic compounds would be adsorbed quickly. After $15 \mathrm{~min}$, adsorption process has been almost completed. From 15-120 min, the effluent COD would be stabilized at 50-55 mg/L and COD removal efficiency was $c a$. 48.6-53.3\%. Besides, there was no desorption phenomena during the whole process. Compared 
with Fig. 2, the reaction time was significantly decreased due to the dosing of OR-SON. And in practical engineering, reaction time was one of the important factors affecting the capital costs and operating costs. Therefore, reducing the reaction time was very important. However, considering the reaction of $\mathrm{H}_{2} \mathrm{O}_{2}$ and organic compounds, which happened on the surface of OR-SON, the reaction time of $1 \mathrm{~h}$ was selected in order to make the reaction completely.

Effect of the dosage of OR-SON on the performance of heterogeneous Fenton oxidation: For more obvious comparison, the initial operating conditions were selected as follows: the dosage of $\mathrm{H}_{2} \mathrm{O}_{2}$ was $50 \mathrm{mg} / \mathrm{L}$, the reaction time was $1 \mathrm{~h}$, the molar ratio of $\mathrm{Fe}^{2+}$ and $\mathrm{H}_{2} \mathrm{O}_{2}$ was reduced to $0.2: 1$ (the molar ratio was one-tenth of the traditional Fenton system) and the $\mathrm{pH}$ was adjusted to $\mathrm{pH} 3$. The effect of the dosage of OR-SON on the performance of heterogeneous Fenton oxidation was investigated and the result was shown in Fig. 6.

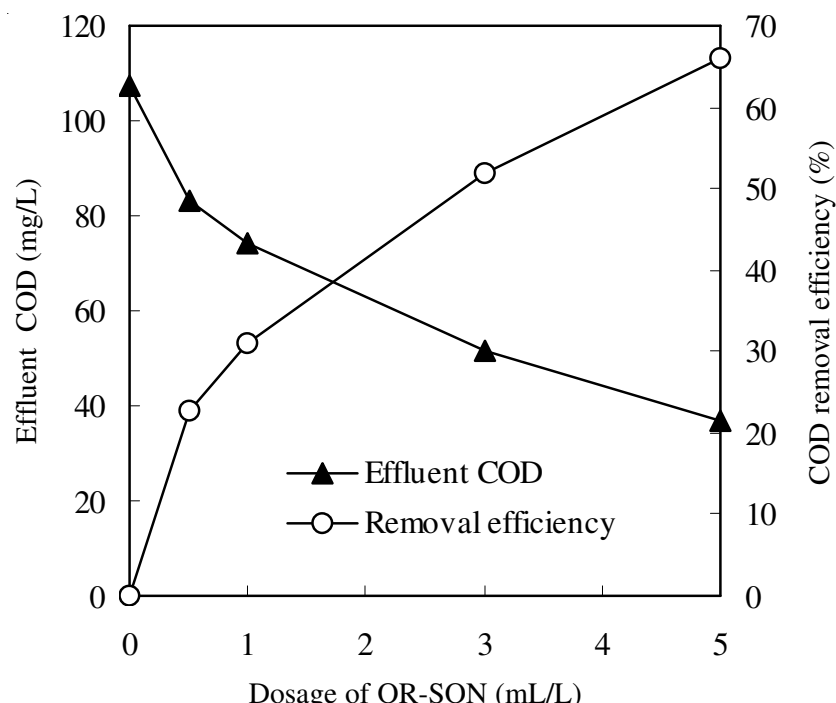

Fig. 6. Effect of different dosage of OR-SON on the performance of heterogeneous Fenton oxidation

In this study, the initial COD of the raw wastewater was $107 \mathrm{mg} / \mathrm{L}$. Fig. 6 shows that the effluent COD decreased with the dosage of OR-SON. As the dosage of OR-SON increased from $0.5-5 \mathrm{~mL} / \mathrm{L}$, the effluent COD reduced from 83.1-36.6 $\mathrm{mg} / \mathrm{L}$ and the COD removal efficiency increased from 22.4$65.8 \%$. Compared with dosing sole OR-SON (Fig. 3), the effluent COD decreased from 45.8-36.6 mg/L under the ORSON dosage of $5 \mathrm{~mL} / \mathrm{L}$. So the dosing of OR-SON could dramatically improve the removal efficiency of organic compounds. The reasons might be more organic compounds adsorbed with the increasing dosage of OR-SON. On the other hand, OR-SON could adsorb the $\mathrm{H}_{2} \mathrm{O}_{2}$ to its surface, which the organic compounds could be degraded by ${ }^{\circ} \mathrm{OH}$ more efficiently. However, in this study, because the dosage of $\mathrm{H}_{2} \mathrm{O}_{2}$ was relatively low, the effect of $\mathrm{H}_{2} \mathrm{O}_{2}$ was not obvious.

Comparison between heterogeneous Fenton oxidation (catalyzed by OR-SON) and traditional Fenton oxidation: Operating conditions of traditional Fenton oxidation were as follows: the initial COD of raw wastewater was $110 \mathrm{mg} / \mathrm{L}$, the molar ratio of $\mathrm{Fe}^{2+}$ and $\mathrm{H}_{2} \mathrm{O}_{2}$ was $2: 1$, the initial $\mathrm{pH}$ was adjusted to $\mathrm{pH} 3$ and the reaction time was $2 \mathrm{~h}$. The effect of the dosage of $\mathrm{H}_{2} \mathrm{O}_{2}$ on the performance of traditional Fenton oxidation was investigated and the result was shown in Fig. 7.

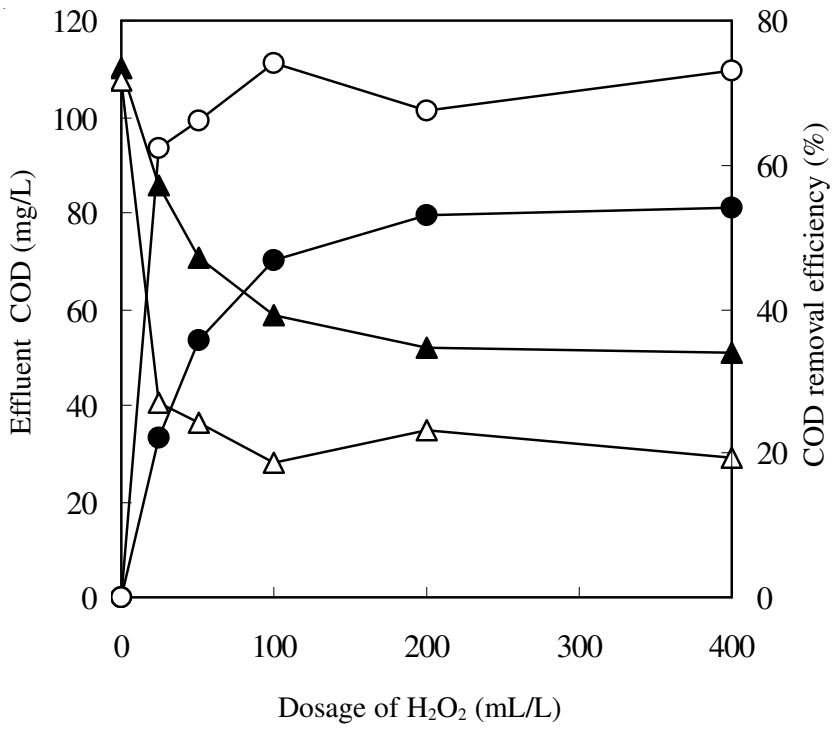

$\triangle-$ Effluent COD of Fenton+OR-SON

- COD Removal efficiency of traditional Fenton

-O- COD removal efficiency of Fenton+OR-SON

Fig. 7. Comparison between heterogeneous Fenton oxidation (catalyzed by OR-SON) and traditional Fenton oxidation

Operating conditions of heterogeneous Fenton oxidation were as follows: the initial COD of raw wastewater was 107 $\mathrm{mg} / \mathrm{L}$, the molar ratio of $\mathrm{Fe}^{2+}$ and $\mathrm{H}_{2} \mathrm{O}_{2}$ was $0.2: 1$, the initial $\mathrm{pH}$ was adjusted to $\mathrm{pH} 3$, the reaction time was $1 \mathrm{~h}$ and the dosage of OR-SON was $5 \mathrm{~mL} / \mathrm{L}$. The effect of the dosage of $\mathrm{H}_{2} \mathrm{O}_{2}$ on the performance of heterogeneous Fenton oxidation was also investigated and the result was shown in Fig. 7.

As shown in Fig. 7, for traditional Fenton oxidation, when $\mathrm{H}_{2} \mathrm{O}_{2}$ concentration was low, the effluent COD decreased with the $\mathrm{H}_{2} \mathrm{O}_{2}$ dosage. However, after the $\mathrm{H}_{2} \mathrm{O}_{2}$ concentration reached about $100 \mathrm{mg} / \mathrm{L}$, the effluent COD was stabilized at $50.7 \mathrm{mg} / \mathrm{L}$ and the COD removal efficiency was $c a .53 .9 \%$. The reason might be ${ }^{14}$ : more ${ }^{\circ} \mathrm{OH}$ produced by excessive $\mathrm{H}_{2} \mathrm{O}_{2}$, resulting in the reaction between ${ }^{\circ} \mathrm{OH}:{ }^{\circ} \mathrm{OH}+{ }^{\circ} \mathrm{OH} \rightarrow \mathrm{H}_{2} \mathrm{O}_{2}$. On the other hand, $\mathrm{H}_{2} \mathrm{O}_{2}$ was the capturing agent of ${ }^{\circ} \mathrm{OH}$, so excessive $\mathrm{H}_{2} \mathrm{O}_{2}$ would produce less ${ }^{\circ} \mathrm{OH}$, so that less organic compounds would be degraded: ${ }^{\bullet} \mathrm{OH}+\mathrm{H}_{2} \mathrm{O}_{2} \rightarrow \mathrm{H}_{2} \mathrm{O}+\mathrm{HO}_{2}{ }^{\bullet}$.

In this study, the addition of OR-SON could significantly improve the removal efficiency of organic compounds. When the initial dosage of $\mathrm{H}_{2} \mathrm{O}_{2}$ and OR-SON was 50 and $5 \mathrm{~mL} / \mathrm{L}$, respectively, the effluent COD was $27.8 \mathrm{mg} / \mathrm{L}$ and COD removal efficiency reached $74 \%$. However, the COD of the effluent was $70.7 \mathrm{mg} / \mathrm{L}$ by traditional Fenton oxidation with the same $\mathrm{H}_{2} \mathrm{O}_{2}$ dosage and 10 times more $\mathrm{FeSO}_{4} \cdot 7 \mathrm{H}_{2} \mathrm{O}$ dosage. Under the same conditions, the COD removal efficiency of traditional Fenton oxidation was only $36 \%$. Besides, the addition of OR-SON could completely solve the problem of residual $\mathrm{H}_{2} \mathrm{O}_{2}$ in the effluent, which occurred in the traditional Fenton oxidation system and affected the reuse of the effluent. 
In this study, the amount of residual $\mathrm{H}_{2} \mathrm{O}_{2}$ increased sharply when the initial dosage of $\mathrm{H}_{2} \mathrm{O}_{2}$ exceeded the proper amount ( $c a .100 \mathrm{mg} / \mathrm{L}$ ). But, in OR-SON Fenton system the residual $\mathrm{H}_{2} \mathrm{O}_{2}$ would be fully decomposed without further treatment.

\section{Repeated use of OR-SON}

Repeated test of adsorption onto OR-SON: The effect of repeated use of OR-SON on its adsorption capacity for wastewater treatment was investigated. The experiment was conducted under the following conditions: the initial COD of the raw wastewater was $110 \mathrm{mg} / \mathrm{L}$, the $\mathrm{pH}$ was adjusted to $\mathrm{pH}$ 3 , the reaction time was $1 \mathrm{~h}$ and the dosage of OR-SON was 5 $\mathrm{mL} / \mathrm{L}$ without $\mathrm{H}_{2} \mathrm{O}_{2}$ and $\mathrm{FeSO}_{4} \cdot 7 \mathrm{H}_{2} \mathrm{O}$ added into the reaction system. After the reaction, the mixture was filtered by a vacuum filter $(0.45 \mu \mathrm{m}$ membrane filter $)$. And the filtered solid residues were put into $1 \mathrm{~L}$ raw wastewater and the test started again. In this study, the repeated test was conducted for 6 times.

Repeated test of heterogeneous Fenton oxidation: The effect of repeated use of OR-SON on heterogeneous Fenton oxidation for wastewater treatment was investigated. The experiment was conducted under the following conditions: the initial COD of the raw wastewater was $110 \mathrm{mg} / \mathrm{L}$, the $\mathrm{pH}$ was adjusted to $\mathrm{pH} 3$, the reaction time was $1 \mathrm{~h}$, the dosage of ORSON and $\mathrm{H}_{2} \mathrm{O}_{2}$ was $5 \mathrm{~mL} / \mathrm{L}$ and $100 \mathrm{mg} / \mathrm{L}$ respectively and the molar ratio of $\mathrm{Fe}^{2+}$ and $\mathrm{H}_{2} \mathrm{O}_{2}$ was $0.2: 1$. The experimental methods were similar to the pervious test except that the repeated test was conducted for 10 times.

After the first use of the OR-SON (only adding OR-SON into the beaker), the effluent COD decreased from 110-32.8 $\mathrm{mg} / \mathrm{L}$. However, its absorption capacity declined dramatically when it was used repeatedly. When OR-SON was used for the third time, the effluent COD rose to $63.1 \mathrm{mg} / \mathrm{L}$ and removal efficiency dropped to $42.6 \%$. When OR-SON was used for the sixth time, the effluent COD rose to $89.3 \mathrm{mg} / \mathrm{L}$ and removal efficiency dropped to $18.8 \%$. Thus, if only relying on the absorption capacity of OR-SON to degrade the organic pollutants, the OR-SON could not be used repeatedly.

However, in OR-SON heterogeneous catalysis Fenton system, although the effluent COD would increase obviously for the 2 nd-4th repeated use of the OR-SON, after the 4th repeated use, the effluent COD would be stabilized at 65-70 $\mathrm{mg} / \mathrm{L}$ which was close to the COD removal efficiency of traditional Fenton oxidation with $100 \mathrm{mg} / \mathrm{L}$ of $\mathrm{H}_{2} \mathrm{O}_{2}$ dosage. However, the $\mathrm{FeSO}_{4} \cdot 7 \mathrm{H}_{2} \mathrm{O}$ dosage of heterogeneous Fenton oxidation was only one-tenth of the traditional Fenton oxidation. After the adsorption of OR-SON was saturated, OR-SON only acted as a catalyst in the Fenton system. Although the catalysis of OR-SON was slightly less effective than $\mathrm{FeSO}_{4} \cdot 7 \mathrm{H}_{2} \mathrm{O}$, it could significantly reduce the amount of $\mathrm{FeSO}_{4} \cdot 7 \mathrm{H}_{2} \mathrm{O}$ required. Therefore, the generation of iron-containing sludge could be reduced extremely.

\section{Conclusion}

During the initial stage, OR-SON had a strong adsorption capacity. When $\mathrm{pH}$ was adjusted to $\mathrm{pH} 3$ and the dosage of
OR-SON was $5 \mathrm{~mL} / \mathrm{L}$, the COD removal efficiency reached $57.2 \%$. In comparison, the COD removal efficiency was only $53 \%$ in traditional Fenton oxidation, until the dosage of $\mathrm{H}_{2} \mathrm{O}_{2}$ dosing reached $200 \mathrm{mg} / \mathrm{L}$. However, the adsorption capacity of OR-SON could not maintain for a long time. When sole OR-SON was added into the beaker, it could not be used repeatedly. When OR-SON was used for the third time, the COD removal efficiency dropped from 70.2-42.6\%. When OR-SON was used for the sixth time, the COD removal efficiency was only $18.8 \%$. OR-SON could strengthen the oxidation ability of $\mathrm{H}_{2} \mathrm{O}_{2}$ and it could substantially increase the reaction rate and COD removal efficiency of traditional Fenton system. Under the operating conditions of $\mathrm{pH} 3$, respective $5 \mathrm{~mL} / \mathrm{L}$ and $50 \mathrm{mg} / \mathrm{L}$ of OR-SON and $\mathrm{H}_{2} \mathrm{O}_{2}$ dosage and $1 \mathrm{~h}$ of reaction time, the effluent COD was $27.8 \mathrm{mg} / \mathrm{L}$ and COD removal efficiency reached $74 \%$. However, for traditional Fenton oxidation, under the same $\mathrm{H}_{2} \mathrm{O}_{2}$ dosage and 10 times more $\mathrm{FeSO}_{4} \cdot 7 \mathrm{H}_{2} \mathrm{O}$ dosage, after $1 \mathrm{~h}$ reaction, the effluent COD was still $70.7 \mathrm{mg} / \mathrm{L}$ and its removal efficiency was only $36 \%$. If a relative satisfactory treatment performance was required, ORSON could be reused for 2-3 times in the OR-SON heterogeneous catalysis Fenton system. If less $\mathrm{FeSO}_{4} \cdot 7 \mathrm{H}_{2} \mathrm{O}$ consumption was required, OR-SON could be reused over 10 times with similar wastewater treatment performance as traditional Fenton system. The dosage of $\mathrm{FeSO}_{4} \cdot 7 \mathrm{H}_{2} \mathrm{O}$ in the OR-SON heterogeneous catalysis Fenton system was only one-tenth of that in the traditional Fenton oxidation. Thus, the generation of iron-containing sludge could be reduced dramatically.

\section{REFERENCES}

1. A. Mahmood, S. Ali, H. Saleem and T. Hussain, Asian J. Chem., 23, 3875 (2011).

2. M.A. Tarr, Chemical Degradation Methods for Wastes and PollutantsEnvironmental and Industrial Application, Marcel Dekker Inc., New York, pp. 165-200 (2003).

3. S. Caudo, G. Centi, C. Genovese and S. Perathoner, Top. Catal., 40, 207 (2006).

4. H. Hassan and B.H. Hameed, Chem. Eng. J., 171, 912 (2011).

5. M.B. Kasiri, H. Aleboyah and A. Aleboyah, Appl. Catal. B, 84, 9 (2008).

6. M.C. Long, J.Q. Lin and Q.Q. Xu, Environ. Pollut. Control Technol. Equipm., 6, 14 (2005).

7. W. Wu, C.C. Wu and Y.P. Zhao, Environ. Sci. Technol., 33, 99 (2010).

8. P. Baldrian, V. Merhautova, J. Gabriel, F. Nerud, P. Stopka, M. Hrubý and M.J. Beneš, Appl. Catal. B: Environ., 66, 258 (2006).

9. J.A. Melero, F. Martinez, J.A. Botas, R. Molina and M.I. Pariente, Water Res., 43, 4010 (2009).

10. N. Al-Hayek and M. Dore, Water Res., 24, 973 (1990).

11. T. Mishra, P. Mohapatra and K.M. Parida, Appl. Catal. B, 79, 279 (2008).

12. R.M. Liou, S.H. Chen, M.Y. Hung, C.-S. Hsu and J.-Y. Lai, Chemosphere, 59, 117 (2005).

13. J.A. Zazo, J.A. Casas, A.F. Mohedano and J.J. Rodríguez, Appl. Catal. $B, \mathbf{6 5}, 261$ (2006).

14. Z. Gao, G.Y. Lei and C.C. Jiang, Acta Sci. Circumstant., 31, 765 (2011).

15. C. He, K.F. Xu, H.X. Xi, J. Zhang, X. Li, X. Gu and Z. Li, J. South China Univ. Technol., 31, 51 (2003). 